\title{
Restorying lived lives in educational research: Storyboarding as a creative space for scholarly thinking in narrative analysis
}

\section{Inbanathan Naicker}

School of Education, University of KwaZulu-Natal, Durban, South Africa Naickeri1@ukzn.ac.za

https://orcid.org/0000-0003-2092-0878

\section{Daisy Pillay}

School of Education, University of KwaZulu-Natal, Durban, South Africa Pillaygv@ukzn.ac.za

https://orcid.org/0000-0001-7152-3974

\section{Sibonelo Blose}

School of Education, University of KwaZulu-Natal, Durban, South Africa

Bloses@ukzn.ac.za

https://orcid.org/0000-0002-7328-6383

(Received: 13 January 2020; accepted: 9 September 2020)

\section{Abstract}

Traditionally, a storyboard has been used in the film-making industry as part of the preparatory process of film production. In this article, we focus on its use as a creative space for analysis in educational research. Specifically, we make visible our learnings, as social science researchers, about storyboarding as an imaginative, tangible, and reflexive space for narrative inquirers to work with the complexity of restorying lived lives in educational research. We draw on Sibonelo's reflections on using the storyboard in his doctoral dissertation and offer our subsequent dialogues on his reflections as the data for this article. Our learnings indicate that storyboarding opens-up researcher subjectivity in the restorying process. In engaging critical friends, it serves as a space for the mediation of multiple perspectives and meanings of participants' lived lives and is an imaginative space in which to filter creatively large amounts of field texts. We thus suggest that storyboarding enhances verisimilitude in the restorying process.

Keywords: critical friend, narrative analysis, narrative inquiry, productive ambiguity, storyboarding, verisimilitude, visual research 


\section{Contextualising our research}

We three are South African academics who teach and research in a School of Education at a South African university. Inbanathan (Inba) and Sibonelo work in the discipline Educational Leadership and Management and Daisy in the discipline Teacher Development Studies. Over the past four years, we have collaborated in a transdisciplinary research learning community providing research support for $\mathrm{PhD}$ students who are employing narrative inquiry as methodology for their studies. Our research learning community is comprised of two research supervisors, Inba and Daisy, and ten students of whom Sibonelo was one. As a research learning community, we met once every six weeks, on a Saturday, for a full-day engagement on various aspects of the research process to enrich doctoral students' knowledge and hone their understanding of, and skills in using narrative inquiry.

Our work in this research learning community is strongly influenced by Eliot Eisner's provocative suggestion to conference delegates at the American Educational Research Association conference in 2012 that we make the research process aesthetic rather than anaesthetic (see Pithouse-Morgan \& Pillay, 2013). As Pillay and Pithouse-Morgan have explained, "When we think of anaesthetic, we visualise a lifeless body, a numbing experience, of how we can deaden minds rather than bringing them to life" (2016, p. 4). Using this analogy has propelled us as educational researchers to consider how we can interrupt the traditional process of working with people's narratives of their everyday lives generated in the field and turn this into an enlivening, connecting, and embodied experience. In aligning with Eisner's (1997) perspective on engaging in educational research as aesthetic, ambiguous, embodied, and connected, much of our work in this research learning community draws on arts-based methods such as collage inquiry, metaphor drawings, poetic inquiry, and visual research.

At each of our meetings, we focussed on different aspects of the narrative inquiry research process. The workshops in which we engaged included a consideration of ethics in narrative inquiry, narrative interviewing, quality standards in narrative inquiry, generating research puzzles in narrative inquiry, using visual methods to generate data in narrative inquiry, and justifying one's research in narrative inquiry. The focus at one of our gatherings was on the aspect of narrative analysis, a process in narrative inquiry that many novice researchers find challenging. At this meeting, we introduced our students to storyboarding. Storyboarding, normally used in the film making industry, is a visual device that is comprised of frames of drawings and/or pictures that capture the essence of particular scenes in a film.

In this article, we endeavour to illustrate the potential of storyboarding as an imaginative, tangible, and reflexive space in which narrative inquirers might work with the complexity of lived lives in educational research. We draw on Sibonelo's reflections on using the storyboard in his doctoral dissertation and dialogues we engaged in about storyboarding as the data for this article. We claim that this article is significant for four reasons. First, the article provides narrative inquirers with a device — the storyboard — with/in which to construct narratives from the large amounts of field texts (data) they generate. Second, the article 
demonstrates how the storyboard develops reflexive thinking in narrative inquirers in the restorying process, thereby pushing narrative analysis to a deeper level. Third, the article extends the scholarly literature on rigour in narrative inquiry by demonstrating how the storyboard can be used to broaden interpretations and re-presentations of the lived lives of people studied by narrative inquirers. Fourth, the article interrupts the traditional linear research process from fieldwork to text work because storyboarding offers a creative material space in which to make visible the researcher's connection with the field texts generated in the research project.

The key question that drives this article is: What are we learning about storyboarding as an imaginative, tangible and reflexive space in which narrative inquirers might work with the complexity of lived lives in educational research? In this article, we begin with an account of our curiosity about the process of restorying lived lives. Thereafter, we discuss storyboarding in educational research, storyboarding and narrative analysis, and Eisner's notions of productive resistance. The research process we observed in this study is then clarified, and this is followed by the representation and discussion of our evidence in the form of reflexive dialogues. We conclude the article by consolidating our thoughts and ideas with regard to the key question that guides this article.

\section{Our curiosity in the process of restorying lived-lives}

Narrative inquiry is a study of stories of lived experience (Polkinghorne, 2007). It is a selfreflexive research methodology that seeks to understand and make meaning of lived experiences through stories that people narrate (Clandinin \& Connelly, 2000). "The study of stories and the 'storying' process is undertaken by various academic disciplines including literary criticism, history, philosophy, organizational theory, and [the] social science[s]" such as education (Polkinghorne, 2007, p. 471). Since stories are fundamental to narrative inquiry in educational research, the process of storying the lived lives of participants needs to produce a credible account. Thus, the question that confronts many narrative inquirers is this: How do we go about the restorying process to produce a trustworthy re-telling? What devices are available to assist us as narrative researchers in the restorying process?

A survey of the research literature reveals a dearth of scholarship on the narrative analysis (restorying) process. Maple and Edwards (2009) confirm the paucity of literature available that explains how to engage with narrative inquiry analysis. James (2017) recounts the onerous processes she had to endure in "moving from collecting 'data' to constructing narratives" (p. 3102). She explained that from conversations with other narrative inquirers it became evident to her that "more detailed accounts are needed . . . in published research" of narrative analysis in narrative inquiry (p. 3103). To address the lacuna in research on the restorying process in narrative analysis as narrative inquirers, we explore, in this article, storyboarding as a space in which to re-construct stories of lived experience in educational research. 


\section{What is a storyboard and what is storyboarding?}

Originally and predominantly, the storyboard has been used in the film-making industry as one of the preparatory processes in film production (Greenberg et al., 2012; Hart, 2008). In the film industry, the storyboard is described and understood as a pre-production and previsualization device designed to give a frame-by-frame, shot-by-shot series of sequential drawings adapted from the shooting script. This device gives the production team a visual record of the film's appearance before shooting begins (Hart, 2008). In composing a storyboard, storyboard artists use frames (drawn rectangular boxes) to capture each scene of the film, and within each frame, visuals are used to represent a particular event in the film (Greenberg et al., 2012; Hart, 2008). Storyboarding, the process of composing a storyboard, helps arrange a story in an emplotted sequence as a visual text of images (Hart, 2008).

In 2011, the storyboard made its appearance in educational research. A group of visual researchers engaged participants in a video production process. To aid data generation, the researchers exposed participants to the storyboard as a device to envision and plan video production (Mitchell et al., 2011). Since these scholars borrowed the storyboard concept from the film industry, their use of it in research was similar to how it is used the film-making industry. They described the storyboard as a visual outline or skeleton made up of a series of drawings or sketches, where each sketch or drawing represents one camera shot (Mitchell et al., 2011). See, also, Labacher et al., (2012). These visual researchers perceived the storyboard as a significant device that allows participants to plan, organize, sketch, write, rearrange scenes, change descriptions, modify, add, or delete parts to create the complete story before video production (Labacher et al., 2012; Mitchell et al., 2011). Although the storyboard is understood as one piece of the video production process, the visual researchers pointed out that the storyboard provided critical data that should be read as visual text in a research process. They institutionalized storyboarding as a method of generating visual data. While the storyboard in educational research is currently recognized as a device for data generation, both as part of the video production method and also as a method on its own, in this research we see a different purpose of the storyboard which we explicate further in the section that follows.

\section{Storyboarding and narrative analysis}

Narrative analysis is about "how the stories are produced" (James, 2017, p. 3104). It is about the process of synthesising field texts into coherent stories by drawing on the three commonplaces of narrative inquiry - temporality, sociality, and place (Clandinin, 2013). Temporality encompasses paying attention to the past, present, and future of participants' lives. The sociality commonly refers to attending to a person's personal conditions (such as their feelings, hopes, and desires) and social conditions (the setting under which people's experiences unfold, such as cultural, social, institutional, familial and linguistic settings) in the narrative. The place refers to the physical boundaries of place or the sequence of places where the inquiry takes place. These factors influence the way field texts are synthesised into 
coherent, emplotted, restoried episodes of a person's life comprised of a succession of incidents with a beginning, middle, and end (Polkinghorne, 2003).

Conventionally, when restorying field texts, the researcher creates a plot outline. Keeping this in mind, "the researcher fills in and links the data elements to other data elements" to produce a coherent story (Polkinghorne, 2003, p. 18). Interrupting this conventional view of restorying the text moves us as narrative inquirers to a more reflective, emancipatory approach of employing storyboarding as a visual, material space that aids the restorying process. In reflecting critically on the use of storyboarding, we highlight how representational forms become points of departure for creative thinking and creating the possibility of multiple stories and perspectives in the production of creative knowledge (Pahl, 2017). Engaging in the reconstruction of the storied narratives as a non-linear process using storyboarding has the potential to create opportunities for narrative inquirers to exercise ethical care and responsibility in the production of the storied texts and, thus, to create something altogether novel (Deleuze \& Guattari, 2014). Our article builds on and intensifies the rich debates on the reconceptualisation of the storyboard as a visible, material space for the creative engagement with self as educational researchers, and a way of opening up the subjective meaning-making of personal experiences into a set of multiple truths and perspectives.

\section{Drawing on Eisner's notion of productive ambiguity}

Drawing on productive ambiguity to conceptualise our collective research process for evoking creative knowledge assisted us in considering how storyboarding as a visual, imaginative, and tangible artefact incites openness and a multiplicity of meaning-making in narrative research and how this might bring about change in our ways of knowing as a community of researchers in the field of education. In this article, we highlight how one doctoral student's experiment with storyboarding the critical, nodal moments of the lives of the research participants, evoked a more reflective, visual, and material space in which to understand the complexity of lived experiences.

Storyboarding as a visual representation of selected critical experiences provokes us as narrative researchers to negotiate the iterative between the insider/outsider with "less closure and more plausible interpretations of the meaning of the [everyday] situations" (Eisner, 1997, p. 8). In reflecting critically on the power of the visual in storyboarding, we explore its potential to enhance different perspectives rather than that of the researcher only (Eisner, 1997).

Framing the storyboard as a space that invites multiple perspectives provokes us as narrative inquirers to engage with the stories of lived experiences in all their complexity. Moving beyond the discourse of propositional language for meaning making, the storyboard, as a visual text, invites ambiguity from an "experiential conception of understanding" (Eisner, 1997, p. 7). As a practical meaning making process, it opens up the traditional linear and restrictive restorying process of illuminating the lived educational worlds we wish to 
understand. The storyboard, as an alternative form of data representation, presents images that acknowledge the variety of ways through which our experiences of the research process are coded. Importantly, as a productive, ambiguous space it becomes a point of departure for how the transformation of the researcher's subjective experience "from the personal to the public can occur" (Eisner, 1997, p. 4). Redirecting and making available the researcher's creative thinking in these transformations, makes it a potent and emancipatory site for researcher learning and for the production of creative knowledge of lived lives (Deleuze \& Guattari, 2014; Pahl, 2017).

\section{Our research process}

The data for this article was generated through a two-fold process. First, we drew on Sibonelo's experience of using the storyboard as a space that assisted with the construction of stories. We worked with his reflections on storyboarding that he recounted in his PhD study (Blose, 2018). Sibonelo's study sought to explore the lived experiences of Deputy Principals leading schools in the different school quintiles. He generated field texts from five Deputy Principals using narrative interviews, object inquiry, and collage inquiry. Second, we drew on some of the dialogues that the three of us engaged in about storyboarding and its use to narrative inquirers in educational research.

After a three-hour storyboarding workshop facilitated by Daisy, Sibonelo explored with greater insight and depth how storyboarding could assist him in working with the vast amounts of field texts he generated about the lived lives of the teachers he studied. Working visually with the storyboard enabled Sibonelo to work practically with the development of the emplotments for the reconstruction of the stories of each of his participants. He used his research puzzle as a prompt to construct a storyboard for each of his participants. Critical moments in each of the participant's lives (their anxiety, desires, wishes, achievements, significant others, and socio-cultural practices) were visually captured by the pictures in the storyboard (see figure 1 which shows an excerpt from one of Sibonelo's storyboards). He opted to use pictures rather than drawing because he felt more at ease accessing pictures from magazines. (The pictures have been blurred for ethical reasons). In developing the visual storyboard, Sibonelo sought the help of his peers from the $\mathrm{PhD}$ research learning community to engage with him in selecting his visuals for it. He was often questioned about why particular pictures were selected and he had to justify these choices to his peers. 


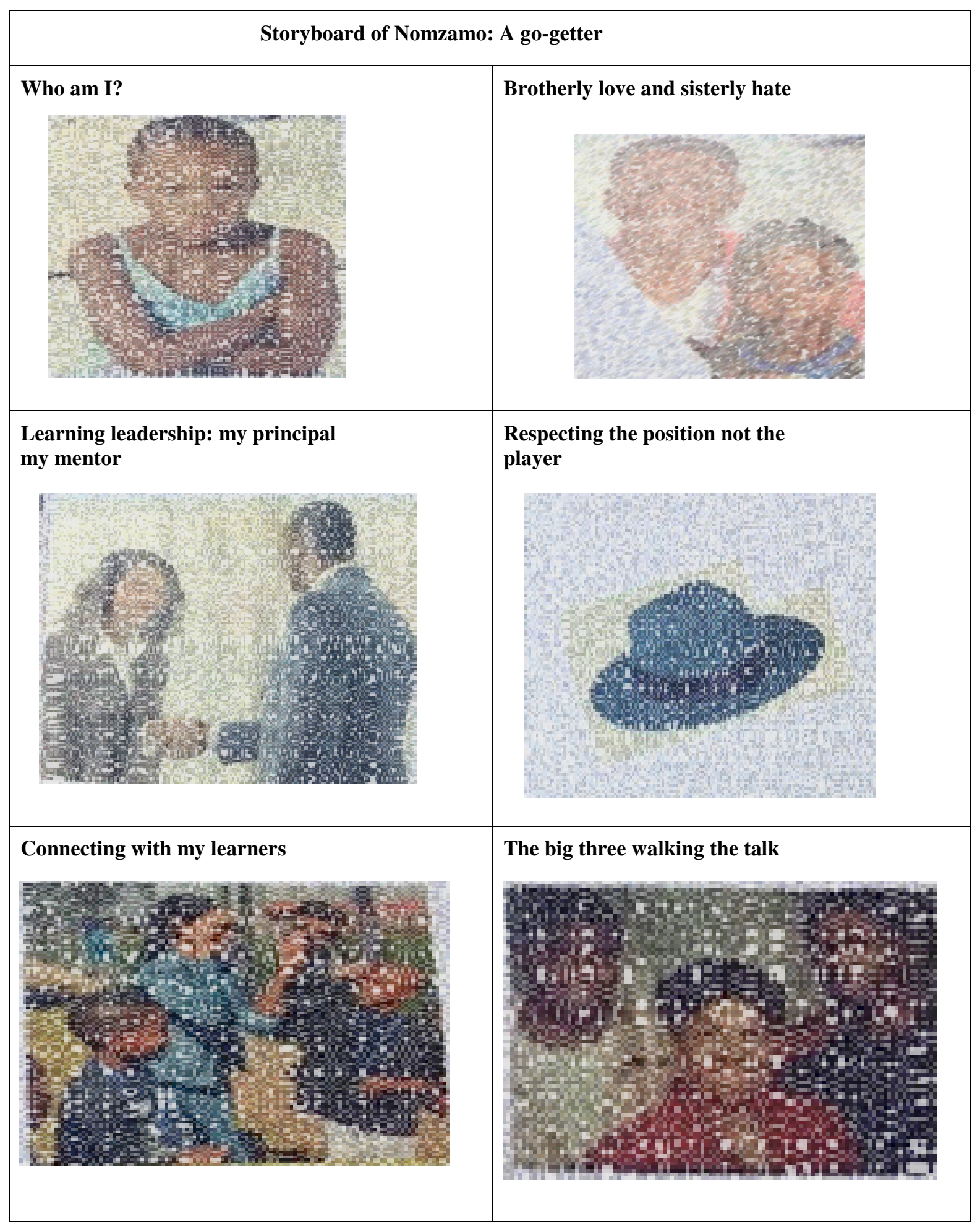

Figure 1: An excerpt from one of Sibonelo's storyboards (Blose, 2018).

To capture Sibonelo's experiences with storyboarding, we decided collectively to (re)present his experiences poetically. We did so for two reasons. First, poetry can be successfully used as a device to condense large amounts of text into a more effective and evocative presentation of it (Langer \& Furman, 2004). Sibonelo's reflections of his experiences documented in his $\mathrm{PhD}$ were quite extensive, so the poetic format helped us to condense and crystallise the narrative text while retaining the crux of the message. Second, poetry "brings the researcher 
closer to the data in different and sometimes unusual ways that can yield new and important insights" (Butler-Kisber, 2002, p. 233). We wanted to connect with Sibonelo's experiences of using the storyboard and, we hoped, through our collective meaning-making, to uncover new understandings of storyboarding as an alternative form of data representation in the restorying process. Hence, we selected excerpts from his $\mathrm{PhD}$ dissertation that reflected why he used the storyboard, how he used the storyboard and in what ways, as a creative, visual space in the re-storying process, it expanded his thinking. We looked through the selected data and highlighted key phrases and words that expressed Sibonelo's experiences of storyboarding. We then used the form of the French-Malaysian pantoum poem in our co-constructed "A Thinking Story Writing Space" to present the key phrases and words because this type of poem, in being comprised of repeated lines, assisted us, in the words of Pillay et al. (2016), "to identify and communicate what we saw as most striking and significant" (p. 4) about Sibonelo's storyboarding experience.

\section{A Thinking Story Writing Space}

Ease narrative analysis

Camera shot

Parts of field texts

Visual outline of sketches

Camera shot

A thinking story writing space

Visual outline of sketches

Develop plots from texts

A thinking story writing space

Parts of field texts

Develop plots from texts

Ease narrative analysis

Following our collaborative poetic inquiry engagement, in a three-day writing retreat we engaged in an analysis of the poem to deepen our co-flexive learnings (Pithouse-Morgan et al., 2015) about the power of storyboarding as an imaginative space in which multiple interpretations of peoples' lived lives can occur. We spent the first day of this retreat discussing the pantoum poem. Our conversations were informed by three key prompts: What does the poem say about storyboarding? How does the poem say it? Why is it worth saying? A version of these three prompts was introduced to us by a colleague who used similar ones to elicit the responses of her English Education students to poetry (see Pithouse-Morgan et al., 2015).

On the second and third day of the retreat, we worked collaboratively on the transcription and decided to represent our conversations as dialogues. As MacInnes and Portelli (2002) have reminded us, dialogues have often been used "for the purpose of discovering information or examining particular phenomena” (p. 33). Given our quest to explore and learn about the 
process of storyboarding as an imaginative, tangible, and reflexive space in which narrative inquirers might work with the complexity of lived lives in educational research, presenting data as dialogue suited our purpose. After a few readings of the transcripts, we clustered excerpts into a sequence of dialogues. We colour coded key ideas and issues that emerged from our dialogues and then grouped them into two themes- "the power of the visual" and "the critical friend as sounding board." We then edited the dialogues lightly to enhance fluidity and coherence.

\section{Findings and discussion}

\section{The power of the visual}

In narrative work, there is a particular emphasis on "how we tell our stories." As narrative inquirers, how we do this "becomes a window to [our] ways of knowing" (Munro, 1994, p. 115). As Emihovich (1994) explained, research scholars using storied accounts, become "storytellers" (p. 37) and taking on this role with responsibility and care requires serious consideration of the truth-value and authenticity of the storied accounts. As narrative inquirers, we recognize that our being comfortable with narrative accounts as sites of scholarship frames meaning making as tentative, shifting, and multiple. The dilemma that confronts us as narrative inquirers lies in finding ways to collaborate with others and construct agreement about shared meaning and ensure that the narrative texts validate many voices, multiple truths, and creative knowledge. We, therefore, need to ask ourselves, "What would it mean to engage in interpretative work in which there are no claims to fixed meanings?"

One way in which educational researchers might choose to make visible their value judgments according to Allen (1995), to ensure the inclusion of many voices and stories, is to interrupt the traditional linear process of field texts becoming research texts in narrative analysis. The use of a storyboard as a visual way of knowing has the potential to make visible the process of data interpretation and meaning making through stories. This visual, transitory process also becomes critical to the educational researcher's making meaning of people's lives. Storyboarding as a visual way of knowing assists researchers in acknowledging that emotion and reason can work in creative material ways to respond to issues of voice, truth, and representation. The reflexive dialogue below highlights the power of storyboarding as visual knowing.

Daisy: For me to select each of the visuals to create the storyboard, I have to consider whether the visual best captures that critical moment. Because I, and not the participant is choosing that visual, I have to know what story the visual is highlighting and the where and when of it.

Inba: Remember that you have to include particular visuals, and there is deep thinking that goes into selecting which visuals you want. There are certain decision-making processes that take place. For instance, why did I choose the picture of a flower over and above the picture of a leaf? 
Sibonelo: Of course . . . visuals trigger thinking . . . they help a researcher to think about and imagine a participant's story to retell it accurately.

Daisy: I have to ask myself as a narrator, 'Does the visual in storyboarding help to open up the story?'

Inba: What thinking informs my decisions about selecting the images for the storyboard I am creating? Is it the research focus and purpose; is it the context in which the research is taking place; or is it all of this?

The process of selecting images for the storyboard offers a creative space in which to allow for different meanings. We recognise the risks researchers take to move beyond their takenfor-granted ways of knowing and engage, instead, with curiosity and imagination (Allen, 1995). As a visual text demonstrating the intersubjective process in the developing of storied accounts, the storyboard has the potential to invite others to participate in the interpretative process since visual images bring to the surface many stories and voices, all of which may advance scholarly thinking and ideas as Pahl (2017) has observed. The researcher's positionality is made available in her or his actively selecting visuals for the storyboard and composing the emerging plot since value judgments are made visible in this way.

The potential impact of the visual in composing storyboards lies in harnessing the power of emotion; the visual and its power to evoke feelings animates the narration, bringing to life the researchers' active co-interpretation in the narration. Storyboarding the researcher's encounter with the data helps to make the research moment an aesthetic experience. As a form of play, choosing "this leaf or that branch" demonstrates the researchers' desire for flexibility. The desire "to see more options" (Allen, 1995, p. 4) deepens awareness and encourages reflection. Thinking visually and making a storyboard involves a practice-based understanding that is an alternative vantage point for productive ambiguity.

Storyboarding, given the power of the visual, offers a way to acknowledge and make visible the intersubjectivity of interpretation as a creative, imaginative process. According to Butt et al., (1992), the relationship of the researcher to the autobiographer (in this case, the research participant), is manifested through the text. As these scholars have noted, making visible the role of the researcher as co-interpreter through storyboarding is crucial. The visual images used to create the storyboard highlight how untold stories can be articulated (Pahl, 2017) as material knowledge that, as a way of understanding self and other, differently disrupts the traditional linearity of the text in a process that generates multiple meanings rather than a fixed reality and singular truth (Bloom \& Munro, 1994).

Storyboarding as a visual representation of critical experiences and lived lives "increases rather than lessens" the understanding of the lives examined (Bloom \& Munro, 1994, p. 110). The power of the visual in the storyboarding activity allows for making meaning of the complexity, ambiguity, and contradictions of lived lives. 


\section{The critical friend as a sounding board}

A critical friend is a trusted colleague who offers alternative perspectives to the researcher's views, "asks provocative questions, provides data to be examined through another lens, and offers critiques of [the researcher's] work as a friend" (Costa \& Kallick, 1993, p. 50). In the literature on self-reflexive research, scholars draw attention to the vital role played by critical friends in the research journey in general and in ensuring rigour in the research process in particular (Samaras, 2011; Schuck \& Russel, 2005). However, we have not yet come across any studies that explore the role of the critical friend in developing a storyboard to aid narrative analysis in educational research. In the dialogue below, an exposition of the pivotal role of the critical friend in the construction of the storyboard is illustrated.

Daisy: I suggest an initial dialogue with a critical friend and then the activity of the storyboard. The conversation with a critical friend is important because that person will ask questions [such as] 'What are important events in the participant's life that you picked up?' Without working with a critical friend, I would create a storyboard with only my experience of the data . . . The critical friend is important because I need, first, to articulate orally what stood out for me about this person's life.

Sibonelo: As you know, my study generated massive amounts of field texts from participants, an average of 45 pages per participant. Therefore, I needed to be very circumspect in selecting parts of field work texts to be included in the research text. I think this is where the critical friend came in for me.

Inba: Then, what is the role of the critical friend? Is it that the critical friend would be asking, 'Why are you choosing to depict this critical moment? How does this critical moment tie-up with the research focus and purpose?'

Daisy: Yah! She or he will ask you why ... what are you leaving out ... what are you including? The critical friend is like a sounding board. This is also a reflexive process because you have to explain what you want to include ... Why this particular moment? This is one way to deal with researcher bias. It is about redirecting my subjectivity so that my truth does not dominate the story.

Inba: The critical friend tries to keep in check one's positionality and also ensure that the research agenda takes precedence over a journalistic agenda. An integral part of the research agenda is to ensure the believability of the story, so the conversation with a critical friend in the storyboarding process improves the believability of it.

When one is developing a storyboard, conversation with a critical friend can help to filter the mass of data generated as field texts (Maple \& Edwards, 2009). Instead of having the researcher work alone in piecing together the storyboard and thereby colouring the story with her or his subjectivity, the critical friend becomes a useful sounding board in keeping the researcher's gaze on key life experiences that are linked to the focus and purpose of the study (Schuck \& Russell, 2005). Thus, the critical friend, as Samaras (2011) advised, is not just a 
"buddy" (p. 75) who affirms the researcher's ontological and epistemological perspectives of the storying process. Rather, she or he gets the researcher "to dig beneath the surface" to "provoke new ideas ... and question the researcher's assumptions" with a view to constructing a storyboard that portrays a balanced view of the participants' lived experience (Samaras, 2011, p. 75). In essence, it is about galvanising the researcher to focus on significant nodal moments in the lived life of the participants so that key "experiences that were previously concealed" become apparent and "new directions become clear" (Graham, 1989, p. 16).

Developing the plot of the storyboard should be viewed as a dialectical process involving the researcher and the critical friend in the dialectical triad of a thesis, antithesis, and synthesis (Popper, 2004). The researcher has to justify to the critical friend what gets included in the storyboard and what is excluded since this is the researcher's thesis based on the key nodal moments of the participant's lived experience. The critical friend, while being supportive of the researcher, then provides critique by raising points that the researcher may not have thought about for inclusion or exclusion from the storyboard (Whitehead \& McNiff, 2006). Essentially, the critical friend provides food for thought to the researcher to re-examine her or his decision-making processes and to re-imagine the emplotments in the storyboard based on new information provided by the critical friend. Any alternative view of the critical friend about the thesis of the researcher provides the antithesis. Through ongoing dialogue between the researcher and the critical friend, the researcher soon arrives at an informed decision (synthesis) of what she or he needs to include in the storyboard. Given such rigorous cognitive and, in some instances, metacognitive processes in the construction of the storyboard, the research agenda is strengthened because the research story that is ultimately assembled is the product of deep co-flexive processes (Pithouse-Morgan, et al., 2015).

\section{Consolidating our learning}

Storyboarding as a visual space evokes and elicits inter- and intra-subjective meaning-making in the restorying process. It offers possibilities for creating a dialogical space for the reconstruction of the storied narrative by providing a platform for working with the range of field texts in practical ways to articulate multiple plausible interpretations of lived lives. In this concluding section, we return to the key question that informs this article: "What are we learning about storyboarding as an imaginative, tangible and reflexive space for narrative inquirers to work with the complexity of lived lives in educational research?" We draw three key learnings from our inquiry.

First, the process and the product of storyboarding allows for researcher subjectivity. While the storyboard is coloured by researcher subjectivity, it also invites other voices (those of critical friends) into the restorying process thereby holding up the researcher's selection of visuals of key moments of participants' lived lives to scrutiny and questioning by others. Through storyboarding, the researcher's voice becomes one of many voices rather than being the sole voice in the restorying process. The storyboard thus becomes a polyvocal, co-flexive space (Pithouse-Morgan et al., 2015) in which the researcher is able to negotiate and justify 
her or his subjectivity to critical friends based on the field texts generated and the focus and purpose of the study. Negotiating one's subjectivity through reflexive dialogues with critical friends contributes to plausible interpretations of restoried lived lives.

Our second learning about the use of storyboarding in this process is that a storyboard is more than just a thinking space. In being a space for action as well, it is a form of visual praxis. Because the storyboard is a co-creation with the help of critical friends, it becomes a space for the mediation of multiple perspectives and multiple meanings. In the mediation process, the thinking of critical friends becomes a resource to help the researcher to rethink the decisions made in terms of the selection of the visuals. This rethinking may necessitate some form of action on the part of the researcher, to either justify the selected visuals as representative of key moments of the lived lives of participants in light of the focus and purpose of the study, or to go back to the drawing board, as it were, and select other relevant visuals.

Third, storyboarding fosters a creative and imaginative space in the restorying process. Our imagination produces images that take us beyond our field texts. It allows us to understand lived lives in their complexity. Our imagination allows us to filter large amounts of field texts through the storyboard. The storyboard as an imaginative space and the field texts produce a third space, one in which lived lives can be reconstructed.

Our three learnings, as explicated above, contribute to a larger agenda of maintaining rigour and establishing quality in the restorying process in narrative inquiry. Our learnings show how storyboarding enhances the verisimilitude of the inquiry so that the stories produced ring true in relation to the lived lives of the participants in narrative inquiry. As a material thinking space, the storyboard contributes to the restoried narratives being real and believable.

\section{Acknowledgements}

We acknowledge gratefully grant funding from the National Research Foundation (NRF) of South Africa (Human and Social Dynamics in Development Grant Number 118539). We further acknowledge that any opinions, findings and conclusions or recommendations expressed in this material are those of the authors and therefore the funders do not accept any liability in regard thereto.

\section{References}

Allen, P. B. (1995). Art is a way of knowing: A guide to self-knowledge and spiritual fulfilment through creativity. Shambhala.

Bloom, L. R., \& Munro, P. (1994). Conflicts of selves: Nonunitary subjectivity in women administrators' life history narratives. In J. A. Hatch \& R. Wisniewski (Eds.), Life history and narrative. Qualitative studies series 1 (pp. 99-112). The Falmer Press. 
Blose, S. (2018). Leading from the middle: Lived experiences of deputy principals across school quintiles [Unpublished doctoral dissertation]. University of KwaZulu-Natal, Durban, RSA.

Butler-Kisber, L. (2002). Artful portrayals in qualitative inquiry. The road to found poetry and beyond. Alberta Journal of Educational Research, 48(3), 229-239.

Butt, R., Raymond, D., McCue, G., \& Yamagishi, I. (1992). Collaborative autobiography and the teacher's voice. In I. F. Goodson (Ed.), Studying teachers' lives (pp. 51-98). Columbia University, Teachers College Press.

Clandinin, D. (2013). Engaging in narrative inquiry. Left Coast Press.

Clandinin, D. J., \& Connelly, F. M. (2000). Narrative inquiry: Experience and story in qualitative research. Jossey-Bass.

Costa, A., \& Kallick, B. (1993). Through the lens of a critical friend. Educational Leadership, 51(2), 49-51.

Deleuze, G., \& Guattari, F. (2014). What is philosophy? Columbia University Press.

Eisner, E. W. (1997). The promise and perils of alternative forms of data representation. Educational Researcher, 26(6), 4-10.

Emihovich, C. (1994). Distancing passion: Narratives in social science. In A. J. Hatch \& R. Wisniewski (Eds.), Life history and narrative: Qualitative studies series 1 (pp. 3748). The Falmer Press.

Graham, R. J. (1989). Autobiography and education. Journal of Educational Thought, 23, 92-105. http://search.ebscohost.com/login.aspx?direct=true $\& \mathrm{db}=\mathrm{eue} \& \mathrm{AN}=508333872 \&$ site $=\mathrm{e}$ host-live

Greenberg, S., Carpendale, S., Marquardt, N., \& Buxton, B. (2012). The narrative storyboard: Telling a story about use and context over time. Interactions, 19(1), 64-69.

Hart, T. (2008). The art of the storyboard: A filmmaker's introduction (2nd ed.). Focal Press.

James, G. (2017). Cul-de-sacs and narrative data analysis - A less than straightforward journey. The Qualitative Report, 22(12), 3102-3117.

Labacher, L., Mitchell, C., De Lange, N., Moletsane, R., \& Geldenhuys, M. (2012). What can a visual researcher do with a storyboard? In E. Milne, C. Mitchell \& N. de Lange (Eds.), Handbook of participatory video (pp. 149-163). Altamira Press. 
Langer, C., \& Furman, R. (2004). Exploring identity and assimilation: Research and interpretive poems. Forum Qualitative Sozialforschung / Forum: Qualitative Social Research 5(2), Article 5. http://www.qualitativeresearch.net/index.php/fqs/article/view/609

MacInnis, C., \& Portelli, P. (2002). Dialogue as research. Journal of Thought, 37(2), 33-44.

Maple, M., \& Edwards, H. (2009). Locating and understanding voice in narrative inquiry: A journey of discovery. In V. Minichiello \& J. Kottler (Eds.), Qualitative journeys: Student and mentor experiences with research (pp. 33-48). Sage.

Mitchell, C., de Lange, N., \& Moletsane, R. (2011). Before the camera roll: Drawing storyboards to address gendered order. In L. Theron, C. Mitchell, A. Smith \& J. Stuart (Eds.), Picturing research (pp. 218-231). Sense Publishers.

Munro, P. (1993). Continuing dilemmas of life history research: A reflexive account of feminist qualitative inquiry. In D. Flanders \& G. Mills (Eds.), Theory and concepts in qualitative research perspectives from the field (pp.163-177). Teachers College Press.

Pahl, K. (2017). Dialogic objects: Material knowledge as a challenge to educational practice. In D. Pillay, K. Pithouse-Morgan \& I. Naicker (Eds.), Object medleys: Interpretive possibilities for educational research (pp. 29-44). Sense Publishers.

Pillay, D., Naicker, I., \& Pithouse-Morgan, K. (2016). Writing academic autoethnographies: Imagination, serendipity and creative interactions. In D. Pillay, I. Naicker \& K. Pithouse-Morgan (Eds.), Academic autoethnographies: Inside teaching in higher education (pp. 1-18). Sense Publishers.

Pillay, D., \& Pithouse-Morgan, K. (2016). A self-study of connecting through aesthetic memory-work. In J. Kitchen, D. Tidwell \& L. Fitzgerald (Eds.), Self-study and diversity (Vol. 2) (pp. 121-136). Sense Publishers.

Pithouse-Morgan, K., Muthukrishna, A., Pillay, G., Van Laren, L., Chisanga, T., Meyiwa, T., Moletsane, R., Naicker, I., Singh, L., \& Stuart, J. (2015). Learning about co-flexivity in a trans-disciplinary self-study research supervision community. In A. Samaras \& K. J. Pithouse-Morgan (Eds.), Polyvocal professional learning through self-study (pp. 145-172). Sense Publishers.

Pithouse-Morgan, K., \& Pillay, D. (2013, September). The opposite of aesthetic is anaesthetic!" Making supervision an aesthetic experience? Workshop presented at the University of KwaZulu-Natal's 7th Annual Teaching \& Learning Higher Education Conference, Durban, RSA.

Polkinghorne, D. (2003). Narrative configuration in qualitative analysis. In J. Hatch \& R. Wisniewski (Eds.), Life history and narrative. Qualitative studies series 1 (pp. 5-23). The Falmer Press. 
Polkinghorne, D. E. (2007). Validity issues in narrative research. Qualitative Inquiry, 13(4), 471-486.

Popper, K. R. (2004). What is dialectic? Vordenker, Summer Edition, 1-24. https://www.vordenker.de/ggphilosophy/popper_what-is-dialectic.pdf

Samaras, A. P. (2011). Self-study teacher research. Improving your practice through collaborative inquiry. SAGE.

Schuck, S., \& Russell, T. (2005). Self-study, critical friendship, and the complexities of teacher education. Studying Teacher Education, 1(2), 107-121.

Whitehead, J., \& McNiff, J. (2006). Action research: Living theory. SAGE. 